\title{
Pedodontist's Role in Managing Speech Impairments Due to Structural Imperfections and Oral Habits: A Literature Review
}

\author{
Jyothi S Bommangoudar ${ }^{1}$, Shashidhar Chandrashekhar ${ }^{2}$, Shruti Shetty ${ }^{3}$, Sandeep Sidral ${ }^{4}$
}

\begin{abstract}
Speech is one of the oldest media of communication of thoughts. It has affected human behavior and progress so greatly that it has been one of the important determinants of psychosocial health of the human beings. The dental profession, as a guardian of oral health, is engaged to a great extent in altering and restoring structures within the oral cavity, to alleviate the ravages of disease and developmental abnormalities. A major portion of speech articulation takes place within the oral cavity, and any alteration or restorations of structures therein will adversely affect speech proportionate to the location and magnitude of alteration. This article provides an updated literature review on the role of pedodontists in early diagnosis and intervention of speech impairments.
\end{abstract}

Keywords: Cleft lip and palate, Oral habits, Speech, Speech impairments.

International Journal of Clinical Pediatric Dentistry (2020): 10.5005/jp-journals-10005-1745

\section{INTRODUCTION}

Child's cognitive development relies mainly on the development of speech and language.

Speech is the process whereby groups of sounds or words are produced by the physical mechanism during the act of communication. ' Language is used to convey meaning with the help of symbols (words) representing objects or events that are organized into patterns (sentences). ${ }^{2}$ Language is governed by a set of semantic (meaning) and syntactic (grammatical) rules.

The conditions that are involved in speech and language problems are unusual voice quality, lack of fluency, articulation disorders, grammatical errors (syntax), vocabulary (semantics), etc. ${ }^{3}$ These problems may or may not appear together. Every effort should be taken to recognize the speech disorders as they may turn into permanent communicative disorder if left untreated.

According to American Speech-Language-Hearing Association (ASHA), expressive language and vocabulary problems can be minimized by early speech and language intervention. ${ }^{4}$

Proper communication plays a significant role in gaining cooperation and providing effective treatment of children. ${ }^{5}$ Pedodontists have significant role in developing dentition as well as the overall development of the child by treating young children with effective communication establishment, because they are more aware of how the oral structures affect the speech. For instance, speech is greatly affected by premature extraction of primary incisors. ${ }^{6}$ This article briefs on how the structural imperfections and oral habits can cause speech impairment and the role of pediatric dentist in overcoming it.

\section{Normal Speech Production and Acquisition Process}

Pulmonary pressure by lungs initiates the speech followed by sound generation by phonation with the help of glottis in the larynx. The vocal tract then modifies this speech into different vowels and consonants. However, speech can also be produced using upper vocal tract which is commonly known as Donald Duck talk.
1,3,4 Department of Pedodontics and Preventive Dentistry, SMBT Dental College and Hospital, Sangamner, Maharashtra, India

2PAHER University, Udaipur, Rajasthan, India; Department of Conservative Dentistry and Endodontics, SMBT Dental College and Hospital, Sangamner, Maharashtra, India

Corresponding Author: Jyothi S Bommangoudar, Department of Pedodontics and Preventive Dentistry, SMBT Dental College and Hospital, Sangamner, Maharashtra, India, Phone: +91 8975798089, e-mail: joepedo121@gmail.com

How to cite this article: Bommangoudar JS, Chandrashekhar S, Shetty S, et al. Pedodontist's Role in Managing Speech Impairments Due to Structural Imperfections and Oral Habits: A Literature Review. Int J Clin Pediatr Dent 2020;13(1):85-90.

Source of support: Nil

Conflict of interest: None

\section{Three Stages of Production}

The production of spoken language involves three major levels of processing: conceptualization, formulation, and articulation. ${ }^{8}$ The first is the processes of conceptualization, in which the intention to create speech links a desired concept to the particular spoken words to be expressed. In the next stage, there will be creation of linguistic form which is needed to phrase the desired message. This stage is known as formulation stage which consists of steps, namely, phonetic encoding, morphophonological encoding, and grammatical encoding. In the last stage, the jaw, lips, tongue, larynx, lungs, glottis, and other parts of the vocal apparatus execute the articulatory score resulting in speech. This phase is called as the articulation stage. ${ }^{9}$

Alteration in the size and shape of oral cavity produces vowel sounds (Fig.1), ${ }^{10}$ whereas consonant sounds are produced by alteration in various musculoskeletal valves linked with speech mechanism (Table $1^{1}$ and Fig. 2). ${ }^{10}$

The cry sound made by the newborns is the initial effort of sound development at birth. ${ }^{2}$ An infant's first babble marks the first stage in the development of speech production, which is fully

(c) The Author(s). 2020 Open Access This article is distributed under the terms of the Creative Commons Attribution 4.0 International License (https://creativecommons org/licenses/by-nc/4.0/), which permits unrestricted use, distribution, and non-commercial reproduction in any medium, provided you give appropriate credit to the original author(s) and the source, provide a link to the Creative Commons license, and indicate if changes were made. The Creative Commons Public Domain Dedication waiver (http://creativecommons.org/publicdomain/zero/1.0/) applies to the data made available in this article, unless otherwise stated. 
converted to developed speech when the child becomes 8 years of age. In speech development, early infancy is the period where there is initiation of vowel sounds that are mastered or pronounced
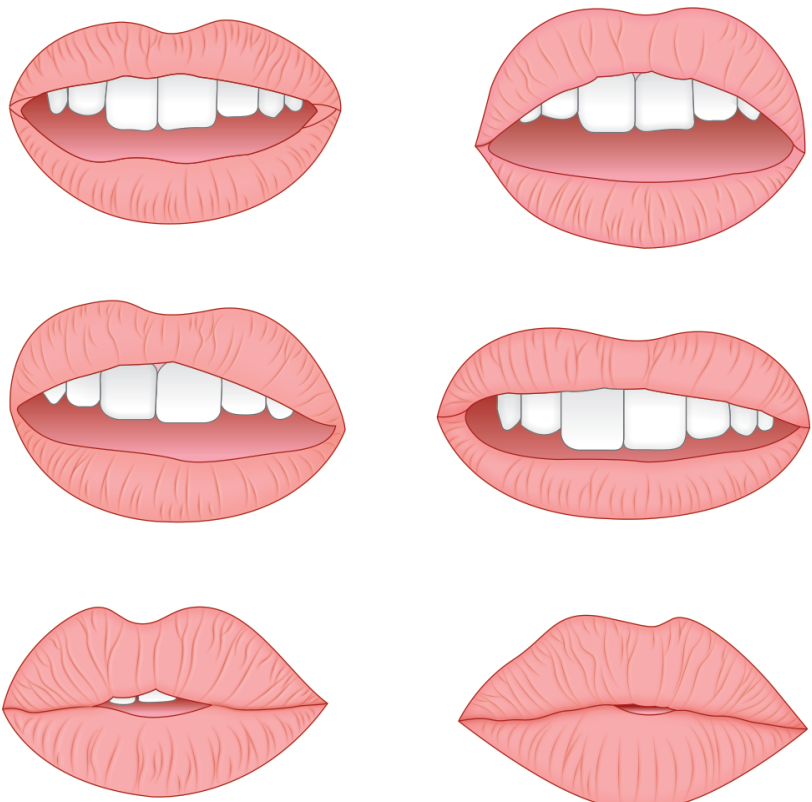

Fig. 1: Change in size and shape of oral cavity

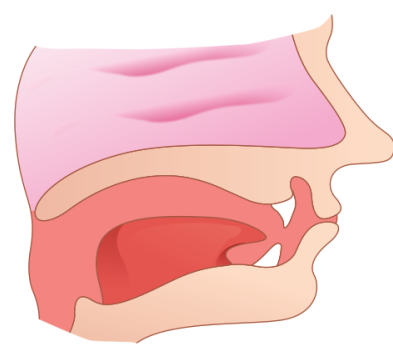

p, b

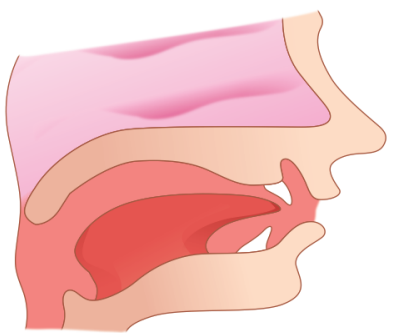

th

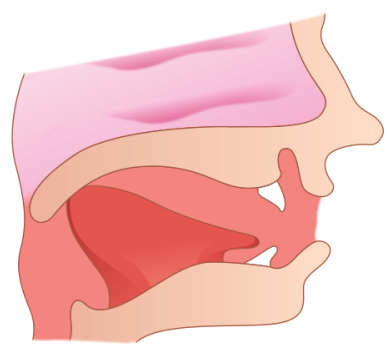

$\mathbf{k}, \mathbf{g}$

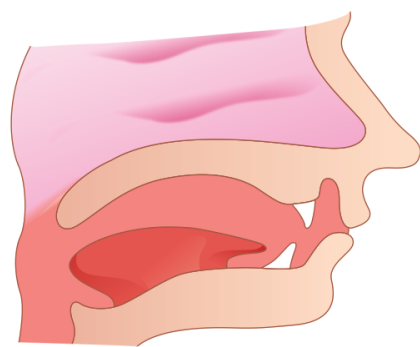

m

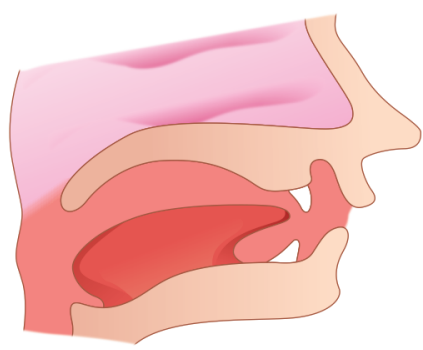

$\mathbf{r}$

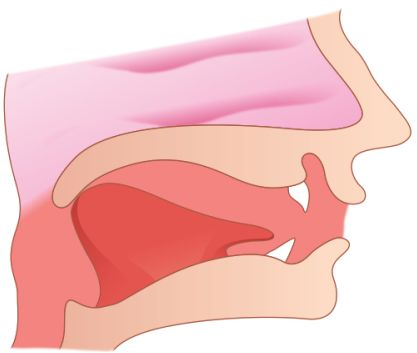

ng well in the next few months; however, more time is required for consonants that are developed in proper order. ${ }^{2}$ The normal pattern of speech development is shown in Table $2^{4}$ and Fig. $3{ }^{4}$

\section{EPIDEMIOLOGY}

The Diagnostic and Statistical Manual of Mental Disorders, fourth edition (American Psychiatric Association, 1994) documented two forms of specific language impairment (SLI), an expressive form and a mixed expressive-receptive form. The prevalence rate for the expressive form was estimated to be between $3 \%$ and $5 \%$ and the mixed form was $3 \%$. Thus, the prevalence rate for both forms of SLI should be between $6 \%$ and $8 \%$ even if enough data are not available. ${ }^{11}$ There is a scarcity in prevalence data of SLI in the Indian population. Speech and language disorders are the most commonly

Table 1: Various musculoskeletal valves associated with consonant sound production

\begin{tabular}{llll}
\hline Place & Valve narrowed & Valve constricted & Valve closed \\
\hline Glottal & & $/ \mathrm{h} /$ & \\
$\begin{array}{l}\text { Linguovelar } \\
\text { Linguopalatal }\end{array}$ & $\mathrm{r} /$ & $\mathrm{k} / / \mathrm{g} / / \mathrm{n} /$ \\
Linguoalveolar & $/ \mathrm{l} /$ & $/ \mathrm{f} / \mathrm{z} /$ & \\
Lingodental & & $/ \mathrm{s} / \mathrm{tf} / / \mathrm{dz} /$ & $/ \mathrm{t} / / \mathrm{d} / / \mathrm{n} /$ \\
Labiodentals & & $/ \mathrm{o} / / \mathrm{q} /$ & \\
Bilabial & $/ \mathrm{w} / / \mathrm{m} /$ & & \\
\hline
\end{tabular}

Fig. 2: Consonant articulation

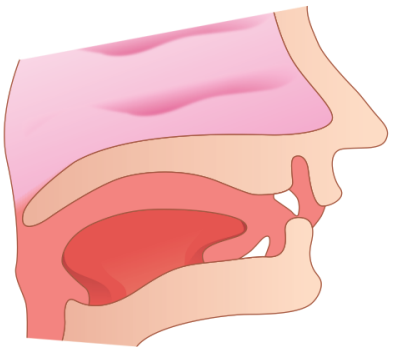

f, v

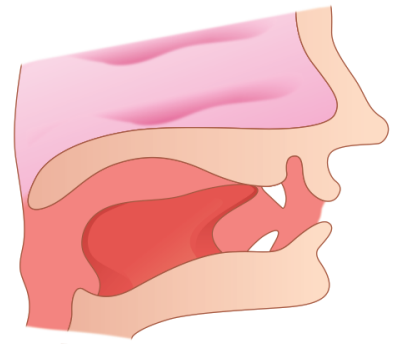

$t, d$

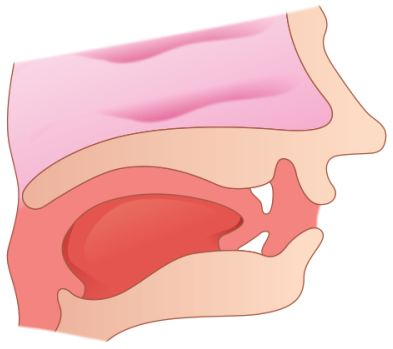

$\mathbf{S}$ 
Table 2: Speech milestones

\begin{tabular}{|c|c|}
\hline Age & Speech \\
\hline \multirow[t]{2}{*}{ 0-3 Months } & Vegetative sounds (grunts, crying) coo, laugh, babble \\
\hline & Smiles at people \\
\hline \multirow[t]{4}{*}{ 4-6 Months } & Coos and babbles when playing alone or with you \\
\hline & Makes speech-like monosyllables, like pa, ba, and mi \\
\hline & Giggles and laughs \\
\hline & Makes sounds when happy or upset \\
\hline \multirow[t]{6}{*}{ 7-12 Months } & Babbles long strings of sounds (bisyllables), like mama, baba \\
\hline & Uses sounds and gestures to get and keep attention \\
\hline & Points to objects and shows them to others \\
\hline & $\begin{array}{l}\text { Uses gestures like waving bye, reaching for "up," and shaking his or her head to } \\
\text { say no }\end{array}$ \\
\hline & Imitates different speech sounds \\
\hline & $\begin{array}{l}\text { Says } 1 \text { or } 2 \text { words, like hi, dog, dada, mama, or uh-oh. This will happen around his or her first } \\
\text { birthday but sounds may not be clear }\end{array}$ \\
\hline \multirow[t]{4}{*}{$1-2$ Years } & Uses a lot of new words \\
\hline & Starts to name pictures in books \\
\hline & Asks questions, like “What's that?", “Who's that?", and “Where's kitty?” \\
\hline & Puts two words together, like "more apple," "no bed," and "mommy book" \\
\hline 2-3 Years & $\begin{array}{l}\text { Put } 2-3 \text { words together to talk about and ask for things, average talking vocabulary is } \\
200-300 \text { words }\end{array}$ \\
\hline 3-4 Years & $\begin{array}{l}\text { Speech is understood } 76 \% \text { of the time. Longer sentences, fluent speech, and more complex } \\
\text { sentences }\end{array}$ \\
\hline \multirow[t]{3}{*}{ 4-5 Years } & $\begin{array}{l}\text { Speech should be } 100 \% \text { understood, might continue to have errors with } s, r, l, v, z, c h \text {, sh, and } \\
\text { "th" and consonant blends (sl, str, bl, etc.) produces long and detailed sentences }\end{array}$ \\
\hline & Tells a short story \\
\hline & Talks in different ways, depending on the listener and place \\
\hline
\end{tabular}

Speech sound developmental norms

Below is a chart reflecting speech sound acquisition. The upper range indicates when $90 \%$ of children have learned that sound. For example, $90 \%$ of children have acquired the "n" sound by the time they are 4 years old; $90 \%$ of children have learned the "s" sound by the time they are 7 years old.

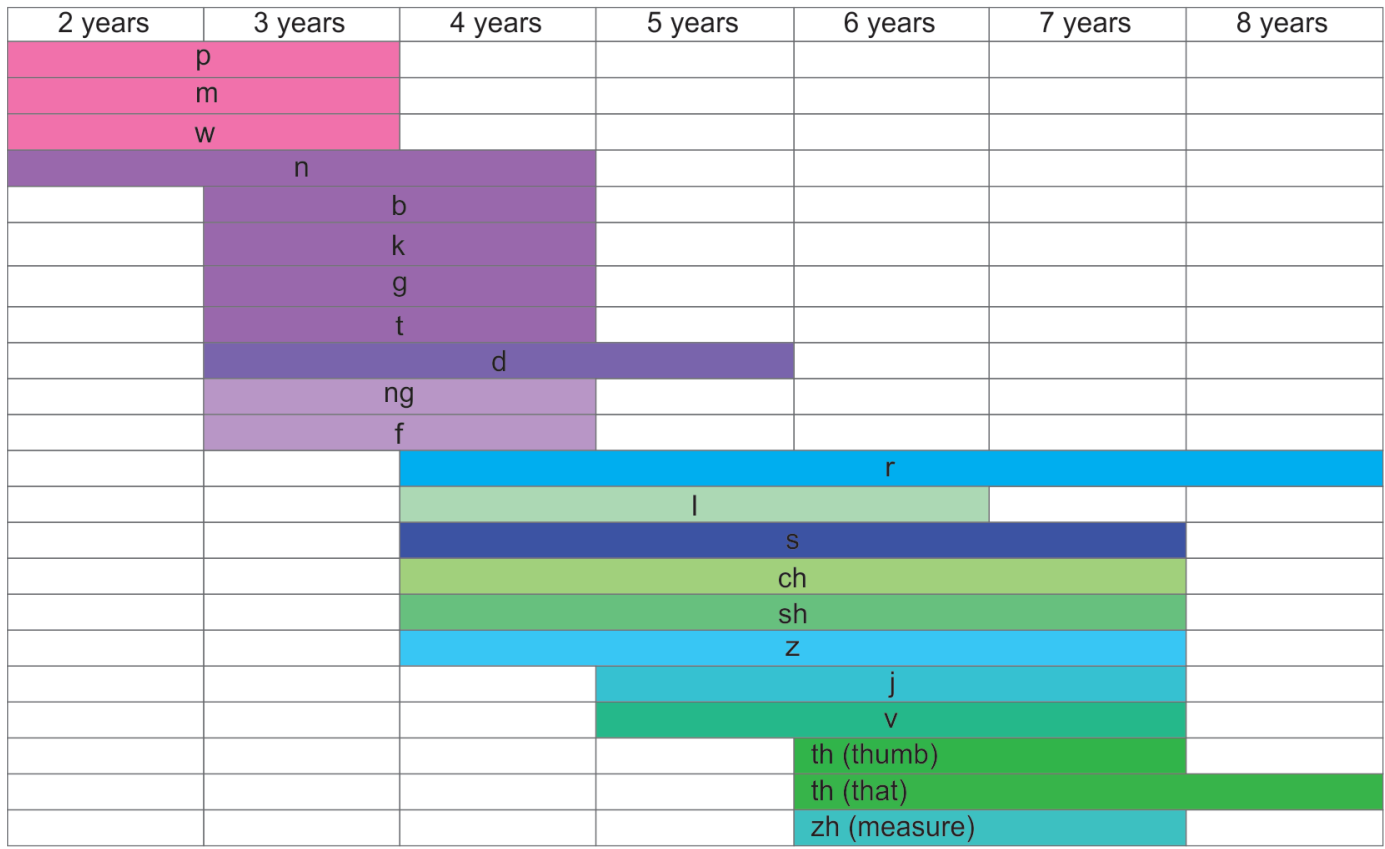

Fig. 3: Speech development chart 
prevalent disorders related to communication, where males are commonly affected as compared to females. ${ }^{12}$

\section{Dental Conditions Associated with SPEeCH ImpaIRMENTS}

The impairments associated with speech and language can be primary, lacking the specific cause for the impairment, or secondary where the impairment is due to another condition or syndrome such as Down syndrome and mental retardation, anatomical defects such as cleft lip and palate and tongue-tie habits such as mouth breathing and tongue thrusting and special conditions such as hearing loss and early childhood caries (ECC). The primary impairments can be effectively treated by speech and language therapy; whereas secondary impairments need the help of healthcare professionals for the correction. ${ }^{13}$

\section{Cleft Lip and Palate}

Speech development in cleft lip and palate patients is deviated, ${ }^{14}$ which is definitely anatomical based resulting from intraoral structural insufficiency. Such speech is characterized by deviant and restricted sound development, lack of labial $(/ \mathrm{p} /, / \mathrm{b} /)$ and lingual $(/ \mathrm{t} /, / \mathrm{d} /, / \mathrm{k} /, / \mathrm{g} /)$ plosives, and dominance of glottal and pharyngeal articulations. $^{15}$

Voice is shaped in the mouth and oropharynx as the adequate velopharyngeal sphincter separates oral and nasal cavities. Hypernasality is mainly due to excessive resonance in nasal cavity which is due to velopharyngeal incompetency. The other conditions that result in hypernasality are fistulae and residual palatal cleft. ${ }^{16}$ Hypernasality due to these conditions can be corrected by occluding palatal fistula which increases intraoral pressure causing improved velopharyngeal movement. ${ }^{17}$ The consonants that depend on nasal resonances are $/ \mathrm{m} /, / \mathrm{n} /, / \mathrm{ng} /$ which are affected in conditions such as inadequate nasal airways, deviated nasal septum, and enlarged adenoids producing hyponasal tone.

Sometimes, the usual tongue position is placed slightly ahead of the alveolus. This causes "fronted" production of the alveolar consonants such as /t $\mathrm{d}$ s/. Few kids make two point contacts between tongue and palate instead of one point contact. This condition is called as double articulation.

The alveolar plosives /t/ and / $/ \mathrm{k} /$ or $/ \mathrm{d} /$ and $/ \mathrm{g} /$ are double articulated as [tk] and [dg], respectively, due to simultaneous contact of both tip and the back of the tongue contacting the palate.

The main components involved in the corrections are behavioral intervention (speech therapy) and surgical correction.

Surgical intervention is required to correct abnormalities of speech occurring from variations in resonance (hyper/hypo nasality), dental- or malocclusion-related defects.

Surgical intervention may involve from presurgical orthopedics (lip taping, lip adhesion, and nasoalveolar molding) to surgeries involving cleft lip, palate, submucosal cleft to correct noncleft velopharyngeal insufficiency (VPI), alveolar bone grafting, and malocclusion.

The aim of speech therapy is to establish normal articulation behaviors. Objectives of therapy are to correct oral placements for consonant misarticulations and establish direction of airflow and appropriate valving of airflow at target place during production of oral sounds.

Low technique tools like the dental mirror is placed under the nostril, stethoscope is placed against side of the nose; the plastic tubing where one end is placed at the nostril entrance and other end at ear; and the nasometer is used for visual feedback. Nonspeech oral motor exercises (blowing, whistling, sucking, and palatal massage) are typically not effective in treating speech errors. ${ }^{18}$

\section{Tongue-tie (Ankyloglossia)}

It is an inherent defect of tongue which is characterized by hindered movement of the tip of the tongue ${ }^{19}$ due to thick fibrous membrane (lingual frenum) which runs from the underside of the tongue to the floor of the mouth. ${ }^{20}$ There is no evidence that tongue-tie causing prevention or delay in the onset of speech. ${ }^{21}$

Pronunciation of "/t///d///n/" requires the use of the tonguetip contacting the palate but can be managed by the body of the tongue. "/I/,/s/,/z/" needs tip to be pointed upward but can also be pronounced pointing the tip downward. Commonly affected sounds are the one containing " $/ r /{ }^{\prime 19}$ By adapting the oral movements, most of the children having the problem of tongue-tie successfully pronounce the above sounds.

The movements of the tongue, such as reaching out to the upper teeth and movement of the tongue forward horizontally are strenuous due to the pull of the lingual frenum.

So people with tongue-tie try to adopt alterations of movements due to limited tongue mobility but unsuccessful since they are often conspicuous or inefficient. A person with tongue-tie often finds it difficult to produce rapid speech with clarity. In such cases, surgical approach followed by speech therapy is needed.

\section{Mouth Breathing}

This pathological condition ${ }^{22}$ results due to obstruction in the upper airway, habit, or sagging facial muscles. A person is said to be a mouth breather if he or she exhibits mouth-breathing habit for a minimum of 6 months. Commonly seen features of mouth breather are change in posture and tone; growth of orofacial structures; and improper movement of cheek, tongue, and lips; all of which result in difficulty in speech, swallowing, chewing, and sleep quality. ${ }^{23}$

Various factors that result in altered speech in mouth breathers are incorrect positioning of tongue, malocclusion and/ or deficiencies in facial growth and development leading to structural problems of oral cavity and flaccid facial muscles. ${ }^{24}$ They have difficulty in pronouncing bilabial $(/ \mathrm{p} /, / \mathrm{b} /, / \mathrm{m} /)$ and fricative $(/ \mathrm{f} /, / \mathrm{v} /, / \mathrm{s} /, / \mathrm{z} /)$ phonemes. Other problems seen in mouth breathers are frontal lisp and lateral lisp. ${ }^{25,26}$ Mouth breathers tend to place the tongue anteriorly during production of lingual phonemes. They also tend to have daytime sleepiness, ${ }^{27}$ immature auditory processing, and poor brain oxygenation, ${ }^{28}$ all of which lead to learning disabilities. ${ }^{29}$

\section{Tongue-thrusting Habit}

It is the condition wherein the tip of the tongue progresses forward between the front teeth to meet the lower lip in the process of swallowing and during speech, so that the tongue becomes interdental. ${ }^{30}$ This habit is related to infantile swallow pattern during childhood and adolescence, resulting in protrusion of anterior teeth and open bite. Patients often have problems while producing $/ \mathrm{s} /$, $/ \mathrm{z} /, / \mathrm{t} /, / \mathrm{d} /, / \mathrm{n} /, / \mathrm{l} / \mathrm{or} / \mathrm{sh}$. Myofunctional treatment is indicated if the tongue-thrust habit is associated with open bite.

This condition does not require any treatment if it is not associated with speech or dental problems or before puberty. Tongue therapy is advised if the habit continues after puberty along with malocclusion. Orthodontic treatment for reposition of teeth is combined with tongue therapy for effective results, rather than 
therapy alone followed by orthodontic treatment. Tongue thrusters are trained to effectively place the tongue posteriorly, with speech therapy modifying the speech errors. ${ }^{31}$

A pediatric dentist may be the first person consulted for professional advice concerning children with speech problems. The study was undertaken to find whether any articulation disorders are associated with the habit of tongue-thrust swallowing, or is it the type of anterior bite that plays an important role in the normal or abnormal speech production in tongue-thrust swallowers. Tonguethrust swallowing is unlikely to produce defective consonant sounds. ${ }^{32}$

\section{Hearing Loss}

Development of receptive and expressive communication skills are delayed by hearing loss. Nearly 17 in 1,000 children under the age of 18 are usually affected by hearing loss. There is direct relationship of its incidence with the age.

There are various causes for impaired communication skills, namely, the age at which the hearing loss occurred, the types of hearing loss, other handicapping conditions, and family support.

The two types of hearing loss are conductive hearing loss and sensorineural hearing loss. Obstruction to sound present in outer and middle ear with normal inner ear is responsible for conductive hearing loss. Whereas impaired inner ear causes sensorineural hearing loss.

Individual's current amplification is checked by sitting close to his or her well-responsive ear's to amplification before the start of the examination. Only audition is used in all tests initially. Examination includes auditory assessment skills, examination of perioral structures, observation of the voice/fluency, and articulation of the speech.

Presence or absence of sound is identified by the patient depending upon individual amplification. Two or more speech stimuli are then discriminated by them. One can start the speech by repeating, pointing to, or writing the speech signal heard.

\section{Early Childhood Caries}

The stomatognathic system is affected by ECC which performs the functions such as breathing, sucking, chewing, and phonoarticulation. All these functions are related to the integrity of dental arch. The early loss of incisors due to ECC may lead to the development of harmful oral habits and altered speech development. ${ }^{33}$ It also compromises the child's quality life, as the early loss of teeth affects Esthetics, nutrition, speech development, dental arch integrity, and development and eruption of permanent successor teeth and contributes to the establishment of deleterious oral habits. ${ }^{34}$

The strategies of myofunctional therapy are isotonic exercises for mobility of the tongue and cheek, isometric exercises to tone cheek, and awareness of the correct chewing pattern.

Previous studies have shown that premature loss of incisor due to previous trauma is unlikely to cause alteration in speech such as lisping. In cases seen, it is usually temporary and disappears once the permanent teeth erupts. ${ }^{35}$

\section{Role of Pediatric Dentist in Identifying and Managing Children with Speech DisORDERS}

The pediatric dentists are helped by awareness of speech delay and speech pathology in finding the right method to correct the child's problem that in turn helps in planning the treatment and management of his/her behavior. ${ }^{3}$ The pediatric dentist having a thorough knowledge of linguistic maturity of child helps in determining the behavior of child in treatment setting can modify their treatment techniques which minimizes miscommunication leading to misbehavior. ${ }^{5,36}$

In dental clinic, speech problems are screened by assessing child's speech-related neuromotor capabilities. It also involves assessment of child's capacity to alter false patterns into right pronunciation after stimulation.

\section{Assessing Speech Sound Production}

This is done mainly to find whether the child uses sounds properly in words and sentences.

In this screening test of speech and sound, the patient is told to count from 1 to 20 . Incorrectly pronounced numbers are recorded by the dentist, giving special focus when the child pronounces the number six, sixteen, seven, seventeen which involves the letter " $\mathrm{s}$ " as this is the main source of pronunciation error and is a difficult sound to master by the child.

The child is made to pronounce a series of sound-in-words items spontaneously in the second portion of the speech sound test. Then the dentist compares the child's sound productions with the age-based data (Table 2) and finds which speech error, if any, involve sounds that the child should have attained at a certain age.

The dentist who engages the child in rapid conversation focusing particularly on those sounds recognized as errors in screening examination will provide additional information about the nature of the error pattern. Professional speech therapy is required for child whose pronunciation errors persist in rapid conversation. ${ }^{37}$

\section{Estimating Neuromotor Status for Speech Musculature}

This can be done with the help of oral diadochokinetic test. The rapid, repetitive movements of particular parts of the speech musculature are assessed with this test.

Certain syllables like "puh", "tuh," "Kuh," and "puh-tuh-kuh" are made to repeat in rapid sequence (15 times per syllable) to check lip activity, tongue-tip activity, the action of the base of the tongue and soft palate, and the overall coordination of the oral structures, respectively, in diadochokinetic testing. ${ }^{1}$

By the age of 5 years, tongue should be able to do minimal intricate movements; at the same time finding it difficult to elevate tongue-tip for "tuh" syllable is considered normal but may not be able to pronounce clearly as the speaking rate is raised. So children are encouraged to speak at a slower rate. Due to larger mass of tongue and sparse sensory innervations of the tongue, the child may not be able to produce "kuh" syllable at faster rate. The dentist assesses child's ability to move the tongue efficiently to produce the "kuh" syllable.

Screening helps in determining whether the child can improve his or her speech with maturation. Usually it is done by special tests called as stimulability tests for spontaneous speech improvement. ${ }^{2}$ Once the child instantly counts and names the screening pictures, stimulability test is done. Error productions made by child is recorded. The child is made to watch the doctor's mouth when he or she correctly pronounces the error item; then the child is made to pronounce the error items/words which are compared with the original response. 


\section{Conclusion}

The production of sound is achieved with the help of neuromotor components of oral structure, whose maturation level is evaluated by the oral diadochokinetic test.

It is possible with screening assessment of speech performance to know whether the child is able to improve error productions on maturation. In that case, the dentist can recommend children for speech therapy. Parents are informed if the screening indicates improvement in speech with maturation.

\section{References}

1. Stewart RE, Barber TK. Pediatric dentistry scientific foundations and clinical practice. London: The C.V Mosby Company ST. Louis Toronto,; 1982.

2. Mason RM, Helmick JW, Unger JW, et al. Speech screening of children in the dental office. J Am Dent Assoc 1977;94(4):708-712. DOI: 10.14219/jada.archive.1977.0321.

3. Shetty P. Speech and language delay in children a review and the role of a pediatric dentist. J Indian Soc Pedodont Preventi Dent 2012;30(2):103-108. DOI: 10.4103/0970-4388.99979.

4. American Speech-Language-Hearing Association. Speech language pathology: medical review guidelines-incidence and prevalence of communication disorders and hearing loss in children. 2008.

5. Pinkham JR. Linguistic maturity as a determinant of child patient behavior in the dental office. J Am Dent Assoc 1977;94(4):708-712.

6. Lamberghini F, Kaste LM, Fadavi S, et al. An association of premature loss of primary maxillary incisors with speech production of bilingual children. Pediatr Dent 2012;34(4):307-311.

7. Weinberg B, Westerhouse J. A study of buccal speech. J Speech Hear Res 1971;14(3):652-658. DOI: 10.1044/jshr.1403.652.

8. Levelt WJ. Models of word production. Trends Cogn Sci 1999;3(6): 223-232. DOI: 10.1016/s1364-6613(99)01319-4.

9. Levelt W. The neurocognition of language. Oxford Press; 1999. pp. 87-117.

10. Jones D. An Outline of English Phonetics. 9th ed., Cambridge: Heffer; 1967.

11. Tomblin JB, Records NL, Buckwalter P, et al. Prevalence of specific language impairment in kindergarten children. J Speech Lang Hear Res 1997;40(6):1245-1260. DOI: 10.1044/jslhr.4006.1245.

12. Konadath S, Chatni S, Lakshmi MS, et al. Prevalence of communication disorders in a group of islands in India. Clini Epidemiol Global Health 2017;5(2):79-86. DOI: 10.1016/j.cegh.2016.08.003.

13. Lawrence R, Bateman N. 12 minute consultation: an evidence-based approach to the management of a child with speech and language delay. Clin Otolaryngol 2013;38(2):148-153. DOI: 10.1111/coa.12082.

14. Russell J, Grunwell P. Speech development in children with cleft lip and palate. In: Grunwell P. Analysing cleft palate speech. London: Whurr,; 1993.

15. Wyatt R, Sell D, Russell J, et al. Cleft palate speech dissected: a review of current knowledge and analysis. Br J Plast Surg 1996;49(3):143-149. DOI: 10.1016/s0007-1226(96)90216-7.

16. Henningsson G, Isberg AM. Influence of palatal fistulae on speech and resonance. Folia Phoniatr (Basel) 1987;39(4):183-191. DOI: $10.1159 / 000265858$.

17. Isberg AM, Henningsson G. Influence of palatal fistulas on veiopharyngeal movements: a cineradiographic study. Plast Reconstr Surg 1987;79(4):525-530. DOI: 10.1097/00006534-198704000-00001.
18. Trost-Cardamone J, Rockville MD. Cleft palate speech: A comprehensive 2-part set. American Speech-Language-Hearing Association. ASHA 2013.

19. Messner AH, Lalakea ML. The effect of ankyloglossia on speech in children. Otolaryngology-Head and Neck Surg 2002;127(6):539-545. DOI: $10.1067 / \mathrm{mhn} .2002 .129731$.

20. Horton CE, Crawford HH, Adamson JE, et al. Tongue-tie. Cleft Palate J 1969;6:8-23.

21. Kummer A. Ankyloglossia: To clip or not to clip? That's the question. The ASHA Leader 2005;10(17):6-7. DOI: 10.1044/leader. FTR2.10172005.6,30.

22. Rodrigues HO, Faria SR, Paula FS, et al. Motta occurrence of mouth breathing and orofacial myology disorders in patients on orthodontic treatment. Rev CEFAC 2005;7:356-362.

23. Branco A, Ferrari GF, Weber SA. Orofacial alterations in allergic diseases of the airways. Rev Paul Pediatr 2007;25(3):266-270. DOI: 10.1590/S0103-05822007000300012.

24. Martinelli L, Fornaro EF, Oliveira CJ, et al. Correlations between speech disorders, mouth breathing, dentition and occlusion. Rev CEFAC 2011;13(1):17-26. DOI: 10.1590/S1516-18462010005000127.

25. Monteiro VR, Brescovici SM, Delgado SE. The occurrence of lisp in eight- to 11-year-old children from municipal schools. Rev Soc Bras Fonoaudiol 2009;14(2):213-218. DOI: 10.1590/S151680342009000200012.

26. Nishimura CM, Gimenez SR. Speech profile of the mouth breather. Rev CEFAC 2010;12(3):505-508. DOI: 10.1590/S1516-18462010005000044.

27. Campanha SM, Freire LM, Fontes MJ. Impact of asthma, allergic rhinitis and mouth breathing in life quality of children and adolescents. Rev CEFAC 2008;10(4):513-519. DOI: 10.1590/S1516-18462008000400011.

28. Vera CF, Conde GE, Wajnsztejn R, et al. Learning disabilities and mouth breathing in subjects with attention deficit hyperactivity disorder diagnosis. Rev CEFAC 2006;8(4):441-455. DOI: 10.1590/ S1516-18462006000400005.

29. Chedid KA, Di Francesco RC, Junqueira PA. The influence of mouth breathing on reading and writing learning in preschool children. Rev Psicoped 2004;21:157-163.

30. Tulley WJ. A critical appraisal of tongue-thrusting. Am J Orthod 1969;55(6):640-650. DOI: 10.1016/0002-9416(69)90040-2.

31. Proffit WR, Mason RM. Myofunctional therapy for tonguethrusting: background and recommendations. J Am Dent Associat 1975;90(2):403-411. DOI: 10.14219/jada.archive.1975.0075.

32. Khinda V, Grewal N. Relationship of tongue-thrust swallowing and anterior open bite with articulation disorders: a clinical study. J Indian Soc Pedod Prev Dent 1999;17(2):33-39.

33. Holan G, Needleman HL. Premature loss of primary anterior teeth due to trauma - potential short- and long-term sequelae. Dent Traumatol 2014;30(2):100-106. DOI: 10.1111/edt.12081.

34. Feitosa S, Colares V, Pinkham J. The psychosocial effects of severe caries in 4-year-old children in Recife, Pernambuco, Brazil. Cad Saude Publica 2005;21(5):1550-1556. DOI: 10.1590/s0102$311 \times 2005000500028$.

35. Gable TO, Kummer AW, Lee L, et al. Preamature loss of the maxillary primary incisors: effect on speech production. ASDC J Dent Child 1995;62(3):173-179.

36. Eyndhoven LV, Chussid S, Yoon RK. , Knowledge, Attitudes, and Practices of Pediatric Dentists Regarding Speech Evaluation of Patients: Implications for Dental Education. J Dent Educ 2015;79(11):1279-1285.

37. Schwartz A, Murphy M. Cues for screening language disorders in pre-school children. Pediatrics 1975;55(2):717. 